\title{
Ideias, mudança institucional, crise e pandemias
}

\author{
Martin Krause $e^{I}$ (D)0000-0002-2811-1699 \\ Universidad de Buenos Aires, Buenos Aires, Argentina
}

Resumo: A recente crise gerada pela pandemia do Covid-19 gerou muitas preocupações imediatas, além de incerteza no que tange aos efeitos sociais que possa ter no futuro. Haverá uma mudança institucional em nossas sociedades? Em que direção: para um maior grau de liberdade ou maior avanço do papel do Estado? Neste artigo, buscaremos analisar como essa mudança institucional é produzida, centrando nossa atenção no papel exercido pelas ideias e valores que predominam na sociedade e como esses evoluem. Particularmente, consideraremos o papel das ideias utilizando como marco de comparação um mercado, no qual encontramos demandantes e ofertantes, destacando o papel que os empreendedores ocupam. Também veremos o que ocorre quando uma crise se desencadeia e em que medida impacta, tanto o tamanho de mercado, como a direção futura que a sociedade possa seguir. Na atualidade, é muito cedo para dizer para onde se inclinará o mercado das ideias depois da pandemia, mas analisaremos qual pode ser o impacto da crise, das possíveis soluções, seus resultados e o efeito sobre as ideias predominantes.

Palavras-chave: Pandemia, crise, ideias, Covid-19.

\footnotetext{
I Professor de Economía, Universidad de Buenos Aires (Historia del Pensamiento Económico na Facultad de Economía e Economía Política de la Facultad de Derecho). Professor en UCEMA (Buenos Aires), OMMA (Madrid). Professor visitante Universidad Francisco Marroquín, Guatemala. Pesquisador na Universidad Empresarial Siglo XXI (Córdoba, Argentina). Membro adjunto no Cato Institute, Washington, D.C. Direção de doctorado. E-mail: mkrause@derecho.uba.ar
} 


\title{
Ideas, cambio institucional, crisis y pandemias
}

\begin{abstract}
Resúmen: La reciente crisis generada por la pandemia del Covid-19 ha generado muchas preocupaciones en lo inmediato, y también incertidumbre respecto a los efectos sociales que pueda tener en el futuro. ¿Se producirá un cambio institucional en nuestras sociedades? ¿En qué dirección? ¿Será hacia un mayor grado de libertad o un mayor avance del papel que el Estado cumple? En este artículo buscaremos analizar cómo se produce el cambio institucional, centrando nuestra atención en el papel que cumplen las ideas y valores que predominan en la sociedad y cómo estas evolucionan. En particular, consideraremos el papel de las ideas utilizando un marco que lo asemeja a un mercado, en el cual encontramos a demandantes y oferentes, y veremos el papel que cumplen los emprendedores. También veremos lo que ocurre cuando se desata una crisis y en qué medida impacta, tanto en el tamaño del mercado, como en la dirección futura que pueda seguir la sociedad. En la actualidad, es muy temprano para decir hacia dónde se inclinará el mercado de las ideas luego de la pandemia, pero analizaremos cuál puede ser el impacto de la crisis, de las posibles soluciones, sus resultados y el efecto en las ideas predominantes.
\end{abstract}

Palabras clave: Pandemia, crisis, ideas, Covid-19.

\section{Ideas, institutional change, crisis and pandemics}

\begin{abstract}
The recent crisis yielded by the Covid-19 pandemic has brought up many immediate concerns, as well as uncertainty regarding the social effects it may have in the future. Will there be institutional change in our societies? In what direction: towards a greater degree of freedom or further advancement of the role of the State? In this article, we will seek to analyze how this institutional change is devised, focusing our attention on the role played by the mainstream ideas and values in society, and how they evolve. Particularly, we will consider the role of ideas using a market as a benchmark, in which we find parties who demand and who offer, highlighting the role played by entrepreneurs. We will also see what happens when a crisis is triggered, and to what extent it impacts both the size of the market and the future path that society may follow. It is too early to say, right now, which way the market of ideas will lean after the pandemic, but we will analyze what may be the impact of the crisis, of the possible solutions, their results, and their effect on the prevailing ideas.
\end{abstract}

Keywords: Pandemic, crisis, ideas, Covid-19. 


\section{Introdução}

\section{O mercado das ideias}

As instituições mudam evoluindo, mas isso não significa um processo espontâneo, no sentido de que "ninguém faça nada". Há agentes que impulsionam essas mudanças, os chamados "empreendedores institucionais". A economia neoclássica tradicional - com sua ênfase em uma conduta maximizadora, em termos monetários, em nível individual - não consegue captar essa função, já que não explica como um empreendedor realizaria os esforços para promover sua proposta de mudança, se posteriormente não se beneficiasse que essas mudanças trazem a outros. Nesse sentido, teria um incentivo para ser um free rider, logo, ninguém se dedicaria a essa atividade. Como então é produzida a mudança a partir desta perspectiva, visto que a análise não fez maiores referências a isso, limitando-se a considerar que simplesmente acontece? Além disso, uma visão baseada no conceito de equilibro não dá espaço à figura do empreendedor.

Mas se tomamos o conceito de equilíbrio como uma tendência dos mercados - que se encontram em desequilíbrio - encontramos a função empresarial destacada pelos economistas austríacos e, então, uma explicação para o empreendedor institucional. Existem exemplos históricos claros desses empreendedores, que assumiram grandes riscos em prol de uma ideia. A princípio, seu benefício não era monetário. No entanto, também se pode obter altas remunerações monetárias no mercado das ideias, o que promove também sua diversidade, auxiliada pela tecnologia. Por exemplo, nunca foram publicados tantos livros.

Esses empreendedores institucionais movimentam o mercado das ideias de um lado para o outro. Geralmente, a população se agrupa em um determinado consenso, mas esse costuma mudar. Nele, as crises ocupam um papel importante: balançam as visões aceitas e abrem caminho para novas interpretações. Nesse sentido, as crises facilitam as mudanças, mas não asseguram sua direção, tampouco se serão benéficas.

Os economistas de maior destaque do século XX destacaram a importância das ideias para explicar as políticas aplicadas e a evolução das sociedades. É famosa a citação de John Maynard Keynes nas notas finais de sua obra Teoria Geral:

as ideias dos economistas e filósofos políticos, corretas ou errôneas, têm mais poder do que se entende comumente. De fato, o mundo está dominado por elas. Os homens práticos, que se acham livres de qualquer influência intelectual, são normalmente escravos de algum economista morto. Loucos com autoridade, que escutam vozes, destilam sua histeria baseados em algum escritorzinho acadêmico de anos anteriores. Tenho certeza de que o poder dos interesses criados é vastamente exagerado quando comparado com o avanço gradual das ideias. Não, obviamente, de imediato, mas depois de algum tempo; porque no campo da economia e da filosofia política não há muitos que deixem influenciar por novas teorias depois de seus vinte e cinco ou trinta anos de idade. Portanto, as ideias que os funcionários públicos e políticos, e até os ativistas aplicam aos eventos atuais provavelmente não sejam novas. Mas, cedo ou tarde, são as ideias - e não os interesses criados -, que são perigosas para o bem e para o mal. (KEYNES, 1936, p. 383) 
Ludwig von Mises (1949) dedica todo um capítulo de sua obra Ação humana (cap. 10) com o título O papel das ideias, no qual afirma que a sociedade é produto da ação humana guiada por ideologias, entendendo-as como a totalidade das doutrinas relacionadas com a conduta individual e as relações sociais, mais doutrinas sobre o "dever ser" e os fins que o homem deveria perseguir. Isto é, o conjunto de teorias científicas sobre os meios, mais uma avaliação dos fins da ação humana. Qualquer situação social é, para Mises, o resultado de ideologias desenvolvidas previamente, que emergem e podem substituir outras existentes, transformando assim o sistema social: a sociedade é sempre a criação de "ideologias" temporais e, logicamente, anteriores. A ação é sempre dirigida por ideias.

No mesmo ano da publicação de Ação humana, F.A. Hayek publicava seu artigo sobre os intelectuais e o socialismo (HAYEK, 1949), que começa assim:

Em todos os países democráticos, nos Estados Unidos ainda mais que em outros, prevalece uma forte crença de que a influência dos intelectuais na política é insignificante. Isto é, na verdade, certo, a respeito do poder dos intelectuais e suas opiniões particulares do momento influenciarem as decisões do voto popular em questões sobre as quais diferem das visões atuais das massas. No entanto, em períodos mais longos provavelmente nunca exerceram uma influência tão grande como a que hoje têm nesses países. Esse poder é exercido moldando a opinião pública. (p. 417).

Hayek define com a palavra "intelectuais" não os autores originais de certas ideias, mas aqueles que as reproduzem, entre os quais jornalistas, professores, religiosos, publicitários, radialistas, escritores de ficção, de humor e todo tipo de artistas. Em outros trabalhos (HAYEK, 1933; 1954), descreveu o processo de difusão das ideias a partir desses autores originais, passando pelos intelectuais, até chegar às grandes massas como gotas que caem em um lago e geram círculos cada vez mais amplos.

Finalmente, Milton e Rose Friedman (1989, s/p) apresentam sua versão dessa mesma teoria nas seguintes palavras:

uma mudança importante na política social e econômica é precedida por uma mudança no ambiente de opinião intelectual, gerado, em parte, por circunstâncias sociais, políticas e econômicas contemporâneas. Essa mudança pode começar em um país, mas, se for duradoura, acaba se difundindo para o mundo. Em princípio, terá pouco efeito na política social e econômica. Depois de um intervalo - às vezes de décadas -, uma corrente intelectual "tomada em seu ponto culminante" se expandirá gradualmente, primeiro lenta, depois rapidamente, ao público em geral e, por meio da pressão pública sobre o governo, afetará medidas econômicas sociais e políticas. À medida que o fluxo de acontecimentos atinge seu ponto máximo, essa corrente intelectual enfraquece, compensada pelo que A. V. Dicey denomina as "correntes de opinião", que representam uma reação às consequências práticas atribuídas à corrente intelectual anterior. As promessas tendem a ser utópicas. Nunca se cumprem e, portanto, desiludem. Os protagonistas iniciais da corrente de pensamento desaparecem, e a qualidade intelectual de seus seguidores e partidários inevitavelmente diminuem. Faltam independência e coragem intelectuais para iniciar uma contracorrente que domine a opinião, e também, embora em menor medida, para se unir à causa. Os jovens empreendedores, independentes e valentes, buscam novos territórios para conquistar, e 
isso requer explorar o novo e o não provado. As contracorrentes que juntam suas forças dão início a uma nova onda, o processo se repete.

De outra perspectiva, temos a visão marxista de Antonio Gramsci sobre a conquista do poder cultural como etapa anterior ao poder político, mediante a ação concentrada dos intelectuais chamados "orgânicos" que se infiltram em meios de comunicação, expressão e universitários.

As ideias, então, cumprem um papel importante na mudança social. E quando falamos de mudança social, nos referimos à mudança das normas pelas quais a interação social é produzida. Mas, como ocorre a mudança das normas?

\section{Evolução ou contrato}

Uma norma é convertida em uma norma geral quando aceita por todos os membros de uma sociedade, permitindo coordenar suas ações. Pode-se dizer que as pessoas chegaram a um "consenso" a respeito dela. Buchanan chamaria isso de um "contrato" social. Em algum ponto a barreira que separa o conceito de consenso e o contrato perde a força, sobretudo quando a palavra "consenso" é interpretada em sentido informal; ou seja, não escrito.

Tomamos um exemplo conhecido, popularizado por Buchanan (2009, p. 47). Se trata dos índios "montanas", na península de Labrador, atual território do Canadá, exemplo mencionado por Demsetz (1987) para explicar a origem dos direitos de propriedade privada. Esse povo utilizava pele dos castores, sobre a qual havia um direito coletivo baseado no controle do território por parte da tribo. Ou seja: a tribo reivindicava e defendia o direito de propriedade sobre certo território, dentro do qual se encontravam os castores, e qualquer membro da tribo podia caçá-los, com exceção de "estrangeiros". Com a chegada dos europeus, iniciou o comércio dessas peles, que originou a conhecida "tragédia dos comuns": cada membro dessa sociedade tinha um incentivo a caçá-los e vender sua pele, impossibilitando um tempo para a reprodução dos castores. Como resultado, o colapso e a extinção teriam ocorrido, não fosse o desenvolvimento de direitos de propriedade "privada", atribuindo parcelas diferentes para cada um, gerando assim o incentivo para proteger um ativo valioso.

Buchanan chama a aceitação desta norma por parte dos lavradores de "contrato". Hayek o teria qualificado provavelmente como resultado de um processo evolutivo inconsciente. Talvez a diferença entre eles esteja no grau de "raciocínio" que atribuem a esses agentes, embora, em ambos casos, a mudança tenha se gerado a partir de certas ideias. Segundo Hayek, estavam motivados por seu interesse pessoal e a compreensão do problema de depredação que enfrentavam, mas não da geração de um "contrato" ou a introdução de uma nova instituição. Os indivíduos de Buchaman seriam mais racionalistas.

Como ficou o acordo, não sabemos. Podemos especular sobre as possibilidades: 
- Uma autoridade da tribo impôs a nova norma (isto significa também que tal norma foi aceita pelo resto, visto que foi cumprida).

- Essa mesma autoridade propôs a norma, que foi aceita pelo resto ou por um grupo representativo do resto.

- Os membros da tribo ou seus representantes se reuniram em assembleia, debateram e adotaram a nova norma. Alguém propôs atribuir direitos de propriedade privados.

- Alguns, ao ver que os castores mais próximos de sua área estavam desaparecendo, começaram a vigiá-la e controlar sua caça; os demais aceitaram, fazendo o mesmo em suas áreas.

- Algum grupo pequeno ou afastado da tribo se relacionava com seu próprio entorno como se fosse "privado", e os demais viram que ali não havia problemas de depredação.

- Surgiu uma noção de propriedade dos castores, que ocorre quando há ameaça de escassez. Dada a primitiva existência da propriedade, como vimos no capítulo 1, inclusive presente em animais e nos antepassados do ser humano, as famílias poderiam ocupar uma área e ser dona dela, mas sem a preocupação de limitar o acesso aos castores, já que não eram da "área de A". Agora que são escassos, "A" formaliza a propriedade e impede a caça predatória.

As três primeiras alternativas se associam com a visão contratualista; as outras três, com a evolucionista. Fica nas mãos dos historiadores determinar qual delas foi adotada, ou se ainda outras diferentes. No entanto, independente do caso, há, pelo menos, um indivíduo que tem a ideia e a leva adiante. Pode ser o líder ou simplesmente alguém que tem a ideia e a propõe, ou o primeiro que decide exercer seu direito preexistente.

A esses que, consciente ou inconscientemente, querem produzir mudanças, chamaremos de empresários institucionais. Esse é particularmente o caso dos autores que sustentam explicitamente a origem das instituições mediante atos criadores deliberados - especialmente um "contrato social" -, como Thomas Hobbes, J. J. Rousseau e, entre os modernos, John Rawls e James Buchanan.

Agora, o primeiro problema que devemos considerar em relação a essa figura - levando em conta que a mudança social tem características de "bem público" -, é como explicar essa função quando o caráter "público" da inovação institucional afirma que prevaleceria o incentivo a ser um free rider ou usuário gratuito do esforço dos outros, já que, na sociedade, não se exclui ninguém dos efeitos das mudanças.

Brennan e Buchanan (1987) apontam corretamente que o modelo econômico tradicional do homo economicus não pode explicar isso. Então, não é de estranhar que, segundo esse marco conceitual, os economistas inclinados a encontrar "falhas de mercado" por todas as partes já argumentem que a provisão de instituições não pode ser "abandonada ao mercado" ou às ordens espontâneas, candidatando-se eles próprios como primeiros provedores de inovações institucionais. No entanto, ao fazer isso, demostram precisamente uma certa iniciativa empreendedora. Por que, então, se mostram tão ativos fazendo propostas de mudanças institucionais se não podem se apropriar dos benefícios dessas mudanças? Para Coase (1994), 
isto é algo natural: os intelectuais atuam precisamente defendendo e divulgando ideias. E mais: Coase se pergunta por que são defensores tão ferrenhos da liberdade no mercado de ideias, defendendo sua liberdade de expressão e pensamento, enquanto não são igualmente firmes na defesa da liberdade no mercado de bens e serviços.

Brennan e Buchanan se perguntam: se as pessoas não agem segundo seu interesse próprio, definido e medido objetivamente, sobre que base atuam? Segundo eles, o economista apresenta uma crítica "efetiva" a quem busca produzir um modelo alternativo com conteúdo preditivo. Mas o problema aqui apresentado é que o economista - com seu modelo de indivíduo maximizador de seu interesse pessoal, econômico e objetivo - não pode prever, nem sequer explicar, por que alguém "faria o bem". Para explicar isso, introduzem uma distinção entre um período constitucional e outro pós-constitucional. No segundo, os custos relativos de promover mudanças institucionais seriam muito elevados, em relação ao incremento de "bem-estar geral" que poderia resultar dessa ação; mas no primeiro, o constitucional, os custos seriam significativamente reduzidos, daí a razão porque o indivíduo que persegue seu interesse pessoal estritamente definido teria um incentivo para atuar em busca desse objetivo.

Não obstante, fica a pergunta: como ocorrem esses períodos constitucionais? Não resultam das ações de alguém? Nesse caso, que motivos os levaram a agir? Os esforços para abrir um período constitucional constituem um "bem público"? Se encontravam em um período préconstitucional, em que os perigos de um Estado hobbesiano de natureza os estimulavam a agir? Ou se tratava de um período pós-constitucional de algum tipo? Não deveríamos considerar que inclusive esse "estado de natureza" seria pós-constitucional em certo sentido, já que, pelo menos, existiria um certo tipo de "ordem espontânea"?

\section{O papel das ideais}

Posteriormente, Brennan e Buchanan simplesmente avançam do âmbito positivo para o normativo, convocando seus colegas acadêmicos a formar uma "religião cívica", que acreditam ser a origem apropriada do processo de mudança institucional, "aceitando o dito por Keynes sobre a influência dos escritorzinhos acadêmicos" no campo das ideias. Mas antes de avançar para o campo normativo, ficam coisas a dizer do âmbito da análise positiva, onde pode estar a ponte entre a mão invisível da evolução espontânea e a ação humana em busca de um objetivo. E dita ponte seria a "mão visível" do empreendedor.

Contribuindo para o ceticismo de Brennan e Buchanan temos os processos "inconsciente" e "não desejados", que envolvem ações na busca de objetivos, claramente opostas às reações "inconscientes" ou "não desejadas"! Mas então, ações conscientes e desejadas por quem, dado que o caráter de "bem público" da mudança institucional garantiria que todos seríamos free riders dos supostos esforços de outros que não podem nos excluir dos resultados que venham a obter?

Devemos retornar ao indivíduo que age com base em escalas de valores subjetivas, que tenta "fazer o bem" por uma variedade de razões. Curiosamente, esse "homem que age" de Mises foi rejeitado por muitos economistas como resultado de uma análise tautológica, no 
sentido de que o interesse individual é tudo que interessa ao indivíduo, embora pareça explicar muito mais que a figura do "maximizador objetivo". Essa visão permitiria explicar as ações de personagens como Bin Laden, Madre Teresa, Hernando de Soto, ou mesmo de acadêmicos que são chamados a participar dessa religião cívica.

Por que agiriam? Ou como dizem Brennan e Buchanan, onde está o equivalente dos lucros empresariais no mercado das ideias? Mas há algumas coisas a serem mencionadas: reputação, prestígio, livros impressos, Prêmio Nobel, honorários por conferências, nomeações em universidades e outras do tipo. E parecem ser um incentivo suficiente para promover a proliferação de textos acadêmicos e de análise e propostas institucionais.

Neste sentido, Brennan, Buchanan e Hayek (1960) têm a mesma posição, afirmando que os esforços deveriam estar dirigidos em grande medida à comunidade acadêmica, por acreditarem que as ideias se originam em pequenos grupos, como de acadêmicos, para depois se espalhar. Hayek utilizou a metáfora de uma gota que cai em um lago: assim ocorre com uma nova ideia que é gerada primeiro em um centro (pode ser Karl Marx escrevendo no British Museum), para depois ir se espalhando, como raios cada vez mais amplos. Milton Friedman utilizou um exemplo similar, considerando a figura de uma pirâmide, na qual as ideias são originadas no topo e depois descem, englobando bases mais amplas, até chegar à base.

Douglass North costumava explicar a mudança institucional como uma reação dos indivíduos a mudanças nos preços relativos, originadas por circunstâncias exógenas: por exemplo, uma peste que dizimava a população e tornava o trabalho escasso. Mas com o passar dos anos e o avanço de suas pesquisas, chegou a compartilhar a mesma perspectiva de Mises, Hayek e Friedman quanto ao papel que as ideias cumprem. Para North, as crenças e instituições que os seres humanos desenvolveram só podem ter sentido como um esforço para encarar a incerteza que enfrentamos em nosso ambiente físico e social evolutivo. Essa incerteza, com a que todos nascemos, se reduz com a experiência, mas os seres humanos têm diferentes interpretações dessas experiências sobre o ambiente, em diferentes culturas ou em diferentes épocas. Portanto, saber como os seres humanos formam suas ideias é essencial para compreender como enfrentam a incerteza. Durante séculos, reduziu-se a incerteza associada ao ambiente físico com o progresso das ciências naturais, eliminando-se explicações baseadas na bruxaria, na magia e nas religiões. Porém, o ambiente social ficou mais complexo e, embora se tenha avançado muito nesse sentido, não são poucos os exemplos de interpretações mágicas ou nada científicas no âmbito das ideias sociais, do qual a economia faz parte. Já vimos no capítulo 4, o predomínio dessas ideias no âmbito das decisões políticas.

Em resumo, North parece achar que o processo de aprendizagem depende da forma como os diferentes sistemas de crenças e valores filtram as informações obtidas da experiência e das diferentes experiências que as sociedades têm em diferentes momentos. Derivam-se dessas visões as regras, as normas informais e os mecanismos de controle que modelam a estrutura institucional, a qual, por sua vez, determina o nível de desempenho econômico. Essa estrutura institucional é composta pela estrutura política do Estado, a estrutura dos direitos de propriedade e as normas e convenções sociais que definem os incentivos informais na 
economia. Nas palavras de North, os sistemas de crenças e visões de mundo são a "representação interna", enquanto as instituições são a "manifestação externa". A cultura, neste sentido, é a transferência intergeracional de normas, valores e ideias, ou a transmissão de nosso "estoque acumulado de conhecimento". (HAYEK, 1960, p. 27).

Poderíamos expor em gráficos a distribuição de uma população com relação a esses valores e culturas como uma distribuição "normal" representada dessa forma, em que o centro do gráfico representa o "consenso" existente em determinada sociedade (Figura 1):

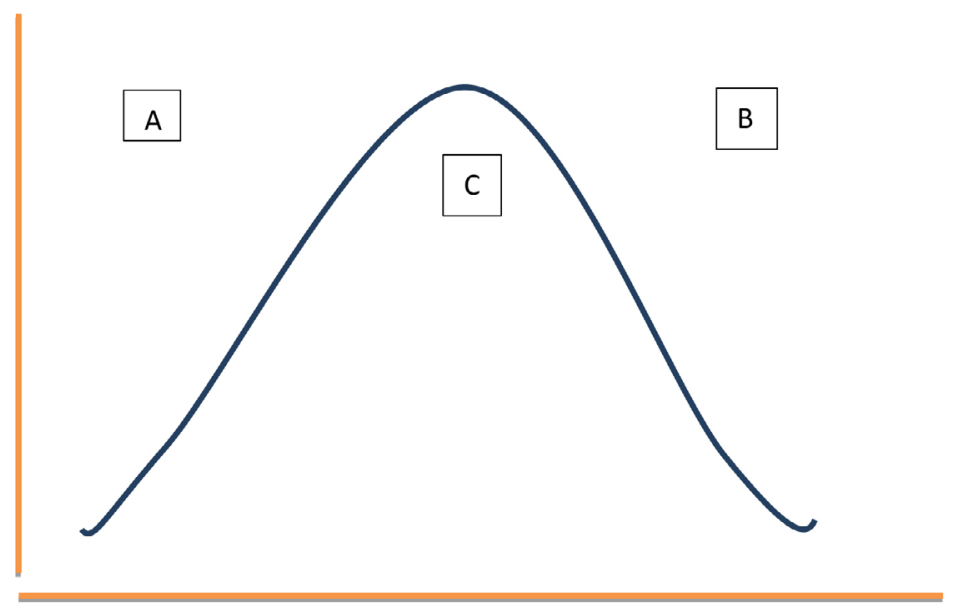

Figura 1. Gráfico da distribuição "normal".

Fonte: Feito pelo autor.

Pode-se relacionar isso com crenças religiosas onde " $\mathrm{C}$ " representa o consenso atual na questão, " $\mathrm{A}$ " sugere menor dedicação à vida religiosa e "B", maior. Ou, poderíamos estar nos referindo às preferências no que tange ao papel que o Estado exerce na sociedade, com " $\mathrm{A}$ " significando uma participação forte e "B", uma participação muito menor, estando o consenso da sociedade em uma posição intermediária. Isso também poderia representar termos políticos, refletindo uma constância entre preferências de esquerda e de direita. No entanto,

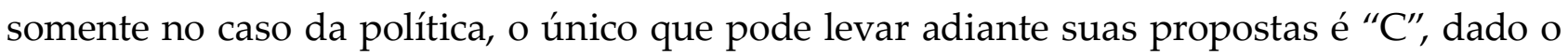
caráter monopolístico do Estado, já que, frente a outras atividades, a situação seria diferente: Se "A" são os budistas, " $\mathrm{B}$ " os protestantes e " $\mathrm{C}$ " os católicos, o gráfico mostra simplesmente que há uma maioria de católicos, mas tanto budistas como protestantes podem se dedicar a suas respectivas crenças, enquanto houver liberdade de cultos. De qualquer forma, nesse momento, o gráfico simplesmente busca destacar que em todos os "mercados de ideias" existem "empreendedores das ideias", ou seja, indivíduos que oferecem diferentes interpretações do mundo, cujas visões competem entre si pela preferência das pessoas. " $\mathrm{A}$ " $\mathrm{e}$ " $\mathrm{B}$ " competem por uma audiência maior, enquanto " $\mathrm{C}$ " defende sua posição e, inclusive, pode aspirar a obter mais apoio. Analisaremos mais adiante o papel desses "empreendedores" e seu paralelo com os que desenvolvem empreendimentos nos mercados de bens e serviços. 
Os empreendedores institucionais podem ser classificados em distintas categorias:

- Empreendedores políticos: os que introduzem as inovações políticas no processo de competição por cargos políticos.

- Empreendedores de políticas: os que se empenham para promover certas políticas, podendo ser organizações setoriais (organizações de produtores, associações profissionais, sindicatos) ou centros de estudos em políticas públicas (think tanks).

- Empreendedores de ideias: os que buscam participar do debate público de ideias, sobretudo em nível intelectual, propondo visões do mundo para interpretar o que acontece.

É certo que as ideias mudam, mesmo que não radicalmente, mas esse consenso pode se deslocar tanto para a esquerda, com para a direita.

Diz-se que a política é "a arte do possível", e é no sentido de que, num sistema democrático de governo, é preciso contar com o apoio - ou, ao menos, não ter a rejeição - da maioria. " $\mathrm{B}$ ” conseguiu um consenso sobre sua visão do problema e do ambiente (" $C$ ", na melhor tradição do político populista, interpreta essa mudança e se posiciona circunstancialmente onde a maioria está, sem maiores convicções ideológicas).

Segundo o gráfico da Figura 2, o eleitor mediano se deslocou à direita (poderia se dizer que isso também ocorreu em muitos países na década de 1990, após o fim do socialismo?) e, no gráfico à direita (Figura 3), o eleitor mediano se deslocou para a esquerda. Esses deslocamentos estariam impulsionados pelo debate no mercado de ideias, propostas por diferentes tipos de empreendedores institucionais. Quando o consenso se desloca tanto para a esquerda como para a direita, permite a implementação de certas políticas que, na situação anterior, não eram possíveis. Quando se fala em países politicamente "estáveis", quem o faz se refere em geral a situações como as do gráfico da Figura 1, onde existe um certo consenso, inclusive com a posse de um governo do outro extremo do espectro político.

Acemoglu et al. (2011) sustenta que, em países com clara fragilidade institucional, existe uma predisposição da curva à esquerda, o que explicaria o predomínio de governos populistas na América Latina. Conforme sua explicação, isso se deve ao fato de que os eleitores temem que os políticos tenham uma agenda "de direitista" oculta, tratando de impô-la após venceram a eleição ou serem cooptados pelas elites. Levando em conta esse temor, os políticos se esforçariam para se apresentar como candidatos de esquerda, e aqueles que buscam ser reeleitos inclusive tentariam convencer o eleitorado de que suas credenciais são autênticas. Até um político moderado buscaria se situar mais à esquerda, para não se mostrar como parte da elite. E os políticos com verdadeiras convicções de direita também enviariam sinais de "esquerda".

Como indicam os autores, o populismo se apresenta como "defendendo os mais pobres" contra as elites, e seu êxito se explicaria pela acentuada diferença na distribuição da renda. Por exemplo, as políticas populistas na América Latina, baseadas em grandes programas de redistribuição e incentivo ao consumo, sempre resultam em algum tipo de crise econômica que prejudica quem supostamente queria beneficiar. O político populista pode estar consciente disso, mas cuidará para que a crise ocorra em um período seguinte. Como os líderes populistas 


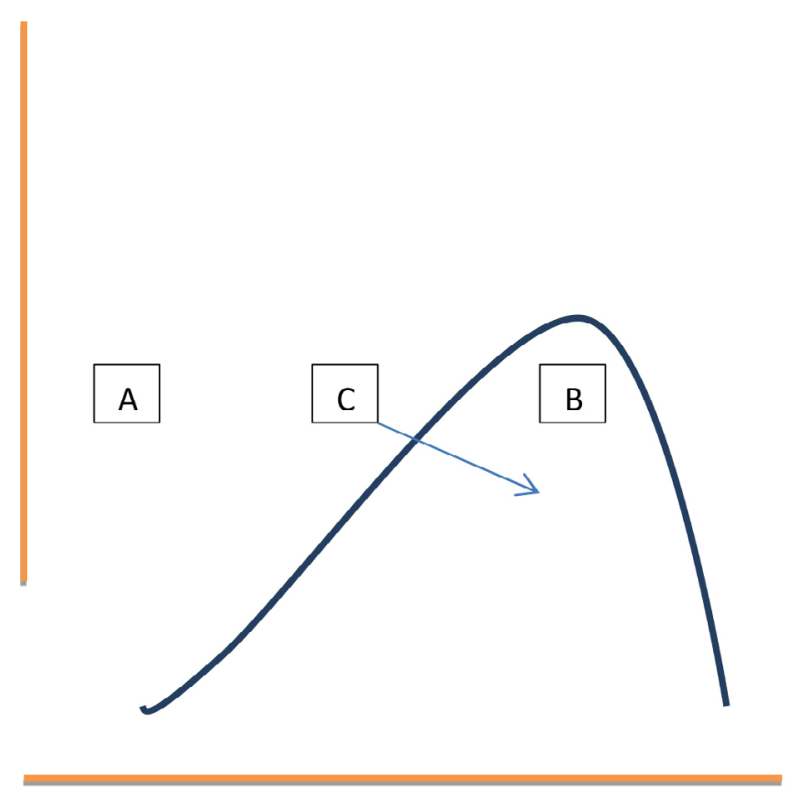

Figura 2. Eleitor mediano - 1980/90

Fonte: Feito pelo autor.

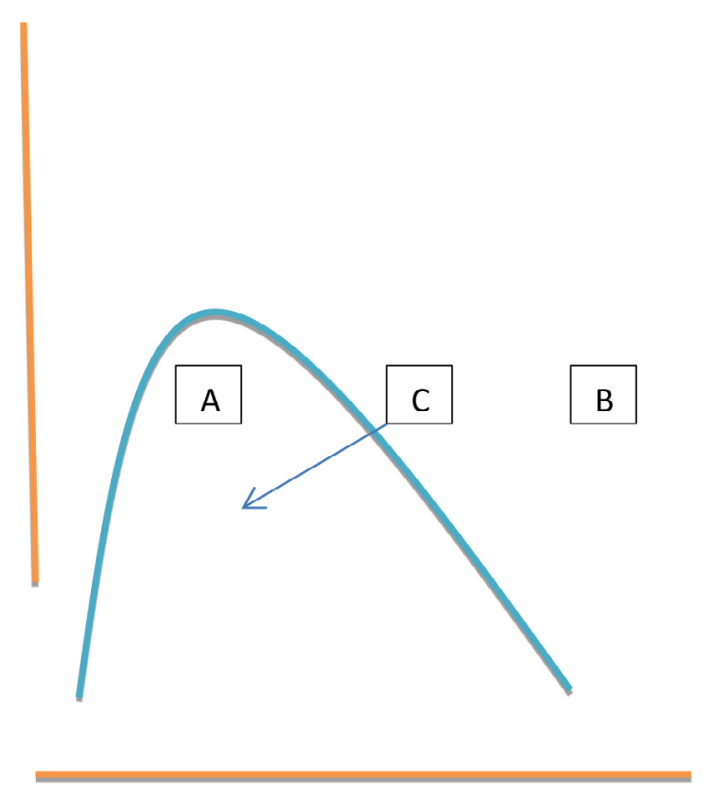

Figura 3. Eleitor mediano - 2000/2010

Fonte: Feito pelo autor.

declaram seu amor pelo povo, mas depois podem vender facilmente sua alma para as elites, o eleitor confiará naquele que apresentar credenciais de esquerda. Até o eleitor mediano, que se encontra no centro do espectro político, terminaria votando nesses candidatos. Embora pareça inevitável essa inclinação à esquerda de qualquer político, ocorrem movimentos das curvas; inclusive o populismo pode ser tanto de esquerda como de direita, interpretado como uma posição não ideológica que busca somente obter o poder, aumentá-lo e mantê-lo, sem importar muito o "conteúdo" da política.

São precisamente as crises econômicas que o populismo gera que possibilitam o deslocamento da curva de opiniões para a direita, onde os empreendedores dessas ideias começam a prosperar quando antes simplesmente subsistiam. Veremos mais adiante o papel das crises na mudança de ideias e na mudança institucional.

A evolução, então, não é "espontânea" no sentido de que simplesmente "acontece", mas sim impulsionada pelos "empreendedores de ideias". Isto é o que a posição de Mises parece implicar quando ele fala da origem das ideias na "mente de um indivíduo" como um tipo de "inovação".

Os empreendedores de ideias competem no mercado de ideias, que se movimentam desde o centro do gráfico ou desde o topo da pirâmide, podem assim influenciar os eventos da sociedade, empurrando-a em uma ou outra direção. Não podemos prever a direção dessa mudança, nem se se tratará de uma melhora. No entanto, existe a possibilidade de que possa ser uma melhora, devido aos avanços no conhecimento e na ciência, com a consequente redução do erro; porém, devemos levar em conta, além disso, que os interesses setoriais não prestarão atenção a esses avanços e, em muitos casos, prefeririam que o erro continuasse. 
Além disso, essas possibilidades existem porque o âmbito da política, onde se canalizam as propostas, não é "perfeito" como mecanismo para expressar as preferências dos indivíduos, e tem suas próprias "falhas".

\section{O empreendedor institucional}

Podemos aplicar a figura econômica do empreendedor a quem busca a mudança institucional? Primeiro, vejamos o papel que o empreendedor ocupa na economia, embora para tal seja necessário superar o modelo neoclássico dominante. Nesse, centrado na análise de situações de equilíbrio e de estática comparativa, em que a mudança de uma posição para outra se produz de forma mecânica, a figura do empreendedor não existe, nem se faz necessária. Não é de estranhar que esse foco tenha dificuldades para compreender o processo dinâmico de mudança.

A noção de equilíbrio está errada e não explica absolutamente nada sobre o funcionamento dos mercados? A resposta é não: não é que não explique nada; o que ocorre é que as suposições que adota limitam sua capacidade para explicar certas condições muito particulares e, provavelmente, deixam sem explicação mais do que esclarecem. Sim, existem forças que empurram para o equilíbrio no mercado; mas, como se parte da suposição de que certas variáveis são dadas e imutáveis, nos ajudam a ver uma cena, mas não o filme completo. Essas variáveis que o modelo do equilíbrio supõe como fixas, chamaremos de "variáveis subjacentes" (KIRZNER, 1997), e são as seguintes:

1. As preferências dos consumidores;

2. A dotação dos recursos;

3. As possibilidades tecnológicas

Abstraímos de possíveis mudanças nelas: (i) os consumidores seguem preferindo o lazer ao trabalho, a cerveja ao vinho, o automóvel à bicicleta, nas proporções atuais. Alguém poderá oscilar de um lado para o outro - do vinho à cerveja, por exemplo -, mas será compensado por outro que faz a mudança oposta, e o conjunto das preferências fica igual. Os recursos disponíveis são os mesmos: não se descobrem novos poços de petróleo, nem aumenta a quantidade de pessoas querendo trabalhar. Por último, a ciência pura pode estar avançando, mas isso não gera aplicações à produção de bens e serviços; tampouco há novas teorias de gestão. No âmbito das ideias e da política, as coisas não funcionam assim.

Nesse contexto, chamaremos de "variáveis induzidas" as que tendem inevitavelmente ao equilíbrio. São elas:

1. Os preços dos produtos e serviços;

2. Os métodos de produção;

3. As quantidades e qualidades dos produtos. 
Então, nesse contexto, o modelo do equilíbrio serve para explicar o funcionamento das "variáveis induzidas". Sua limitação provém da circunstância de que as "variáveis subjacentes" estão em constante mudança. Cada vez que mudam as preferências dos consumidores, novos recursos ou tecnologias são descobertos, e as variáveis induzidas se movem para perto do equilíbrio. É fácil entender que essas mudanças ocorrem de forma permanente, e muito mais rápido hoje em dia, já que a economia nunca está em equilíbrio, mas sempre em "processo" de readequação às novas circunstâncias.

Aqui é que surge o papel do empreendedor e das oportunidades de ganhos "empresariais". Empreendedor é aquele que percebe as mudanças antes dos outros e, ao agir, põe em movimento as variáveis induzidas, para que gerem o possível novo equilíbrio que determina as novas variáveis subjacentes. É como disparar em um alvo, melhorando cada dia mais a pontaria, para então descobrir que o alvo muda de lugar, e que é necessário melhorá-la ainda mais.

$\mathrm{O}$ "processo de mercado", então, é a descoberta das mudanças ocorridas e das oportunidades agora presentes; em um processo de equilíbrio. Por certo, não descarta o erro, pois, de outra forma, não poderíamos explicar as perdas. Nessas tentativas de aproveitar as oportunidades que apareceram em razão das mudanças nas preferências, na dotação dos recursos ou nas possibilidades tecnológicas, pode haver erros, inclusive alguns que nos afastam do equilíbrio. No entanto, esses erros, assim como as tentativas bem-sucedidas, geram informação e contribuem, a seu modo, para descobrir a forma de satisfazer as novas circunstâncias.

No caso das ideias e da política, as variáveis seriam similares: os preços dos produtos e serviços poderiam se assimilar aos impostos e todo custo atribuído à produção de bens e serviços por parte do Estado; os métodos de produção podem incluir se sua produção deveria estar em mãos do Estado ou do setor privado, e as quantidades e qualidades também se referem a esses mesmos bens e serviços. O empreendedor institucional é aquele que descobre que houve mudança nas preferências dos cidadãos, alteração na dotação de recursos ou criação de novas possibilidades tecnológicas, elaborando uma "ideia" ou "proposta" de mudança no marco institucional. No mercado, o empreendedor consegue essa informação por meios muito diferentes: mudanças nos preços de produtos ou insumos, estatísticas sobre a evolução do mercado, estudos sobre a conduta ou preferências dos consumidores, pesquisas etc. Existem métodos muito sofisticados para detectar leves mudanças na preferência dos consumidores. Na política, há diferenças: não existem preços claros como no mercado, e a revelação geral de preferências políticas é obtida em uma eleição que só ocorre de tempos em tempos, e não de forma contínua, como no mercado. Mas os políticos recorrem a pesquisas e outros tipos de estudo de opinião para saber o que os eleitores estão pensando. Qualquer eleição - seja local, regional ou nacional - será tomada como um sinal do qual se pode tirar alguma conclusão sobre a evolução das preferências.

Além das diferenças e semelhanças que possam existir dentro da função empresarial no mercado e na política, no mercado os empreendedores têm de agir também como empreendedores institucionais, sobretudo em muitos países emergentes, para que possam surgir instituições de mercado (LI et al., 2006, p. 358). 


\section{Não sei o que não sei}

No entanto, o processo de descoberta no mercado não é constituído por atos deliberados de aprendizagem; isto é, aqueles que se originam de uma situação em que "sei o que não sei" e, portanto, conheço a forma como obter o conhecimento, como quando um empreendedor contrata um agente de seguros ou um contador. Mesmo que se exija iniciativa para realizar essas contratações ao iniciar um negócio, não é isso que caracteriza, na prática, a função do empreendedor. $\mathrm{O}$ tipo de conhecimento obtido no processo de descoberta no mercado é do tipo "não sei o que não sei", que se caracteriza pela falta de consciência da própria ignorância.

Israel Kirzner (1997, p. 137), que orienta nossa reflexão, apresenta um exemplo sobre a existência de dois preços diferentes no mercado: suponhamos que existam duas fruteiras no mesmo bairro e alguém compra maças em uma delas por $\$ 2 / \mathrm{kg}$. Poderia ter comprado na outra, mas simplesmente desconhecia a sua existência.

O modelo do equilíbrio explicaria o que ocorre aqui da seguinte forma: a informação sobre a diferença de preços se espalharia, fazendo com que os consumidores trocassem de fruteira, reduzindo a demanda na mais cara e aumentando, na mais barata. Inclusive, haveria uma oportunidade para arbitrar, comprando barato na que cobra $\$ 1$, vendendo noutro lugar por menos de \$2. Essas ações tenderiam a unificar o preço no mercado. Mas, como essa informação é difundida? Pode-se dizer que é o resultado de um esforço deliberado; neste caso, que as pessoas sabem que pode haver diferenças nos preços e, portanto, busca encontrá-las: quer dizer, "sabe o que não sabe e assume o custo de obter tal informação". Por que isso não foi feito antes? A resposta de Kirzner é que o início desse processo de difusão de informação ocorre por meio de descobertas espontâneas.

E essas descobertas ocorrem por sorte em alguns casos; mas, principalmente, pela perspicácia de alguns que estão mais atentos a essas diferenças, agindo de acordo. Ou seja: o empreendedor exerce seu papel em um mercado claramente em "desequilíbrio", já que as oportunidades de negócios que encontra são, precisamente, uma confirmação dessa situação. Elas estão aí presentes, mas nem todos as veem: só aqueles que têm a perspicácia empreendedora. É o que ocorre com um quadro, por exemplo: muitos passam por ele, mas apenas um indivíduo perspicaz entende que tem diante de si uma obra com potencial de mercado. O empreendedor institucional que tem êxito, também, é aquele que soube interpretar essa mudança ocorrida na sociedade, e por isso sua proposta tem mais chances de sucesso.

Nesse ponto, é importante entender qual é a função do empreendedor e a diferença que há entre essa e a do capitalista. Em muitos casos, ambas são cumpridas pela mesma pessoa, mas é necessário compreender que estamos falando de duas coisas diferentes, pois, frequentemente, alguém tem uma "ideia" brilhante, porém outro investe o capital para executá-la. A função empresarial é a primeira. Nesse sentido, a função do empresário não é a de "economizar", como faz qualquer participante do mercado, segundo o modelo de equilíbrio. Nesse caso, toda a atividade econômica consiste em atribuir recursos escassos a múltiplos fins, e o que se 
exige é ter a capacidade de fazê-lo da forma mais "eficiente" possível. Mas isso parece mais uma questão para engenheiros do que para empreendedores.

Sem dúvida, é preciso desenvolver os métodos mais eficientes, e essa será uma tarefa de todo empreendedor, mas sua principal contribuição principal não é essa - para isso contrata um bom engenheiro -, mas sim a "criatividade": a tarefa de identificar os meios e os fins. Uma vez conhecidos, entra em ação o engenheiro para atingir a máxima eficiência. $\mathrm{O}$ consumidor tem fins específicos em relação a seu consumo, procurando gastar suas receitas da forma mais eficiente possível; o proprietário dos recursos buscar obter deles o melhor resultado.

A função empresarial, como tal, não exige que o empreendedor tenha meios, mas sim que reconheça as oportunidades: os produtores podem ter vendido a preços inferiores aos que poderiam ter obtido ou os recursos poderiam ter sido utilizados de forma diferente para a produção de coisas que os consumidores precisam de forma mais urgente. Os compradores podem ter pago preços mais altos do que poderiam.

Isto significa que há dois tipos de funções empresariais, que se relacionam com o funcionamento do mercado: uma é a empresarial pura; outra é a maximizadora. Podem ser centralizadas na mesma pessoa ou algumas pessoas sendo empresários puros e outras, maximizadores. Os maximizadores são aqueles que, conhecendo as discrepâncias existentes no mercado (devido à mudança das variáveis subjacentes), procuram aproveitá-las de forma eficiente. Como foi dito, essas funções podem estar presentes em uma única pessoa ou em várias; em uma única pessoa, mas em proporções distintas: existe aquele que tem ideias geniais, mas é incapaz pô-las em prática eficientemente, ao passo que existe aquele que não é necessariamente criativo, porém é organizado e capaz de organizar os processos necessários para prosperar. Isso também implica uma diferença entre um "produtor" e um "empreendedor". Podem haver muitos "produtores" que não necessariamente desenvolvem uma "função empresarial", já que não inovam, não estão alertas às mudanças no mercado, limitando-se apenas a acatar as mudanças vindas dos empreendedores e a responder a elas da forma mais eficiente possível. O empreendedor é o motor do mercado, quem detecta as mudanças e mostra o caminho: o produtor, como tal, não necessariamente cumpre essa função, mas sim a de continuar pelo caminho indicado.

O "produto" ou "serviço" que o empreendedor institucional promove é uma reforma institucional, uma plataforma política. Depois, além da ideia, precisará estruturar uma organização que lhe permita implementá-las, o que exigirá uma função gerencial, como também ocorre no mercado. Estará assim mesmo especulando, tanto sobre a concretização de sua proposta quanto sobre os resultados que seriam obtidos. 


\section{O capitalista}

A outra grande função que deve estar presente no mercado é a do capitalista. É a de quem assume o risco de investir os fundos necessários para desenvolver um empreendimento e esperar seu sucesso ou fracasso, já que obtém o resultado residual, que pode ser positivo (lucros) ou negativo (perdas).

Trata-se de uma função distinta, mas não menos importante. Como dissemos, essas funções podem coincidir na mesma pessoa, mas também podem estar separadas: o empreendedor pode contratar um gerente maximizador e obter capital de um banco ou de um capitalista de risco, que assume o risco, mas não gerou a ideia nem gerencia o negócio. No caso dos empreendimentos pequenos e das empresas familiares, essas funções tendem a estar unidas, porém as grandes empresas geralmente começam como pequenas iniciativas e depois recebem aportes de capital dos acionistas, até que, finalmente, crescem, e a ação maximizadora fica nas mãos dos gestores.

Os economistas franceses do século XVIII tinham uma ideia clara dessa função, de tal maneira que a própria palavra é de origem francesa: entrepreneur, celui qui entreprend (aquele que tem iniciativa). Parece que a palavra foi utilizada pela primeira vez por Richard Cantillon (1680-1734), depois por Anne-Robert-Jacques Turgot (1719-1781) e Jean-Batiste Say (1767-1832). Eles tiveram uma concepção mais ampla dela do que os economistas britânicos Smith e Ricardo, os quais focavam nos fatores de produção e sua remuneração em termos de proprietários, não de empreendedores.

Talvez o economista que mais abordou essas questões é o austríaco Joseph Schumpeter (1883-1950), de quem herdamos a famosa expressão "destruição criativa" que retrata o empreendedor que gera novas indústrias que vão substituindo outras antigas. Schumpeter (2008, p. 84) pensava que o empreendedor rompia o equilíbrio através de sua motivação criadora, enquanto outro austríaco, Ludwig von Mises (1881-1973) e seu aluno já citado, Israel Kirzner, entenderam que a ação do empreendedor leva ao equilíbrio. Essa diferença parece pequena, mas não é, em especial para a economia, já que levava Schumpeter a atribuir ao empreendedor a geração dos ciclos econômicos, enquanto que, para Mises, esses se originam devido às políticas monetárias dos bancos centrais: portanto, duas abordagens muito distintas.

Frank Knight (1885-1972) propôs uma visão do empreendedor como aquele que assume riscos que não podem ser transferidos a um segurador (como é o caso do incêndio de uma casa ou a batida de um carro), mas o mesmo Schumpeter lhe respondeu corretamente que se o empreendedor obtivesse seu capital de um investidor a uma taxa fixa de juros, esse assumiria o risco de o projeto fracassar e o empréstimo não ser pago. Se o risco fica no investidor, qual é o papel do empreendedor?

Salvo na questão das causas dos ciclos, poderíamos dizer que as visões de Schumpeter e Kirzner são similares na medida em que atribuem à função do empreendedor essa capacidade de ver o que outros não veem, de ter iniciativa e criatividade. Existe, porém, uma diferença adicional: para Schumpeter (1951, p. 82), essa habilidade é limitada a poucos - aos inovadores 
revolucionários que mudam o panorama por completo; para Kirzner, essa mesma perspicácia estaria presente em todos, só que em níveis diferentes.

\section{O empreendedor institucional e político}

Como transportar esses conceitos à função de quem promove as mudanças institucionais? Segundo o enfoque de Kirzner, o empreendedor seria aquele que está alerta à mudança nas condições, encontrando ali uma oportunidade. Um exemplo clássico seria o da luta na Inglaterra contra as Leis dos cereais, encabeçada por Richard Cobden e John Bright de Manchester. Em 1815, os proprietários de terras haviam conseguido o fim do livre comércio de grãos e o preço do milho havia subido muito, atingindo diretamente o orçamento da população pobre. Entendendo a importância desse problema, criaram a Liga Anti-leis dos cereais em 1838, foram eleitos para o Parlamento e conseguiram aboli-las em 1846. Pode-se dizer algo parecido de Juan Perón que, percebendo que os anos de isolamento econômico durante a I Guerra Mundial e a crise da década de 1930 tinham desenvolvido um forte setor industrial local e uma mão de obra capacitada, viu uma oportunidade para desenvolver seu projeto político e promover a mudança institucional.

A partir da perspectiva de Schumpeter, o empreendedor institucional é quem realiza uma inovação que "sacode" o mercado. O caso de Karl Marx pode ser sido o mais impactante, a ponto de influenciar toda a atividade política global durante o século 20. Sua inovação, o "socialismo científico", teve um êxito esmagador, e ele não somente cumpriu aqui o papel do empreendedor que gera "destruição criativa" (SCHUMPETER, 2008, p. 83), mas também o de organizador do movimento socialista internacional. Entre outros casos, menciona-se o exemplo do reverendo Jerry Falwell, que começou atuando como um pastor fundamentalista, porém incorporou uma visão política conservadora em sua atividade religiosa, formando um movimento chamado Maioria Moral, que chegou a ter grande influência na política estadunidense. Falwell "inovou" porque, ao contrário de outros pastores protestantes, abriu seu movimento a católicos, judeus e mórmons conservadores (DUFFY, 2007). Algo similar poderia ser dos que iniciaram o "Tea Party" nos Estados Unidos, o movimento MeToo ou a luta contra a mudança climática.

Em outro momento, Schumpeter (2000, p. 222) chamaria de "resposta adaptativa" essas novas condições que foram geradas, e de "resposta criativa" as inovações que revolucionam a forma de fazer as coisas. Na política, como no mercado, existem ambos: alguns produzem as mudanças; outros veem que aconteceram. Um enfoque que reconciliaria as visões de Kirzner e Schumpeter seria aquela em que o empreendedor institucional tem um componente "kirzneriano", alerta à mudança de circunstâncias, e um componente "schumpeteriano", criativo, para oferecer a inovação.

A frequência de "respostas criativas" depende, segundo Schumpeter, da qualidade do capital humano da sociedade, da qualidade relativa nesse âmbito particular de ação, e das decisões individuais e pautas de conduta. Veremos aqui outros fatores que influenciam na existência de empreendedores, seja na quantidade ou no tipo de atividades que promovem. 
O "capitalista" seria aquele que tem um capital "político" e está disposto a investi-lo em certas ideias e propostas. Esse poderia ser também o caso de alguns políticos que têm êxito eleitoral, "investindo" esse capital em seu próprio programa de governo ou noutro que percebem ser o ideal para o momento. Tomemos, como exemplo, o caso de Alberto Fujimori no Peru. Tinha um capital importante, venceu as eleições, mas nem por isso tinha uma visão clara sobre como sair da grave crise econômica em que se encontrava o país. Mesmo assim, teve a perspicácia de escolher uma equipe de colaboradores e um projeto econômico de reformas de mercado que terminaram resolvendo a crise e motivando mudanças respeitadas até hoje, inclusive por outros governos.

Um dos elementos fundamentais é, certamente, o ambiente institucional que influencia a existência de oportunidades para a mudança. Baumol (1990, p. 893) aponta que a proporção dos empreendedores que se dedicarão a empreendimentos produtivos ou a "caça à renda" (inclusive o crime organizado), variará segundo o marco de incentivos que a sociedade ofereça. Isto significa que o tipo de atividades que o empreendedor tentará desenvolver dependerá dos incentivos oferecidos pela estrutura institucional. Se a mesma promove a "caça à renda", predominarão os empreendedores lobistas que buscam privilégios para si ou para seus clientes. Mas entendamos um problema desse argumento: se a estrutura institucional determina o tipo de atividade empreendedora, como pode haver um empreendedor institucional tentando mudar precisamente essas normas? Baumol não responde essa pergunta.

O empreendedor de "políticas" ou de "ideias", como classificados antes, não precisam necessariamente ser os que levam as reformas adiante. De toda maneira, são necessárias as funções do capitalista e do gerente, já que todo o esforço na elaboração de propostas de ser financiado por alguém e sua promoção exige uma atividade gerencial. No mercado, certamente, essas funções podem coincidir em uma só pessoa ou estar divididas. O investidor pode estar financiando um centro de pesquisas, pesquisadores elaborando as propostas de reformas, e um gerente, promovendo-as. O empreendedor "político" é o que compete para obter o controle do Estado, permitindo-lhe implantar seu programa de ação.

Quais são os ganhos que motivam os empreendedores institucionais? Podem ser monetários ou não monetários. No segundo caso, é basicamente a satisfação de implementar uma proposta para alcançar um tipo de sociedade, ou melhorar a existente de alguma forma que gerará melhor qualidade de vida e a adoção de certos valores; no primeiro caso, podem ser tanto vantagens econômicas para certos setores como vantagens pessoais. Os grandes investimentos feitos em campanhas eleitorais sugerem que esses últimos podem ser importantes (HOLCOMBE 2002, p. 155).

Algumas teorias explicam as motivações que mobilizariam esses empreendedores a buscar mudanças nas regulações:

- A teoria da "praça de pedágio", segundo o qual as mudanças nas regulações são impulsionadas por funcionários políticos e governamentais com vistas a aumentar suas possibilidades de obter rendas.

- A tradicional teoria do "interesse público" de Pigou, segundo a qual o funcionário busca promover o bem geral e resolver problemas e falhas de mercado. 
- A teoria do "interesse particular", desenvolvida pelos economistas de Chicago (Stigler, Pelzman, Becker), segundo a qual certos setores promoverão mudanças regulatórias que limitem a concorrência, mesmo que possam favorecer a desregulamentação se os custos das regulações forem muito elevados.

- A teoria do "giro súbito", do guru do management Edward Deming, segundo a qual os empreendedores políticos reagem diante de qualquer crise propondo o caminho oposto ao que vinha sendo seguido. Se a regulação fosse restritiva antes da crise, proporiam desregulamentar; caso fosse leve, proporiam regular. Sugere que esses agentes não têm a menor ideia do que seria uma política adequada, reagindo automaticamente às circunstâncias.

\section{Crise e mudança}

A estrutura institucional não apenas determina a quantidade e o tipo de empreendedores institucionais, mas também influencia muito nas possibilidades de que esses empreendedores vejam suas propostas implementadas. Alguns autores (SCHELLENBACH, 2007; WOHLGEMUTH, 2008) sustentam que diferentes circunstâncias restringem as possibilidades de mudança, dentre as quais, destacam:

- o sistema institucional de divisão de poder, freios e contrapesos das democracias modernas que exige altos níveis de consenso e, portanto, torna pouco provável o êxito de propostas ousadas de mudança;

- os níveis de consenso nas visões gerais sobre o ambiente social;

- as barreiras à entrada de competidores no mercado político.

No primeiro caso, a mudança institucional é mais complexa pela existência de diversos agentes com poder de veto às iniciativas propostas. No segundo, esses modelos mentais compartilhados dificultam a mudança já que essas propostas ou atacam e enfraquecem o status quo, ou requerem níveis elevados de aceitação para avançar. Se for assim - como vimos nos gráficos do capítulo 4 sobre a unanimidade e a quantidade de indivíduos necessária para tomar uma decisão política - só as propostas que obtêm um grande consenso têm chances de sucesso.

Uma crise impacta os modelos mentais predominantes, pois mostra algumas falhas neles; mostra que o status quo é insustentável; exige abrir a mente para novas interpretações e explicações. Isso é o que torna mais fácil a mudança nessas circunstâncias. Uma crise gera incerteza em um número de pessoas que exige informação que permita recuperar a confiança no funcionamento das instituições vigentes ou, simplesmente, novas propostas. Quando o número de indivíduos desiludidos é muito grande, é difícil gerar essa informação: faz-se necessário um "choque de confiança". Não existe uma forma específica de produzi-lo, mas é certo que deve ser suficientemente poderoso para mudar as expectativas das pessoas e, sem dúvida, deverá ser mais poderoso quanto mais profunda e avançada seja a crise. Pode ser um 
simples anúncio, um gesto político, uma desvalorização, uma liberação de preços, a mudança de um ministro e até a saída de um governo. O empreendedor é aquele que está "alerta" a essa necessidade de um "choque de confiança", pronto para lançar a "inovação" que pode gerá-lo.

Além disso, a crise gera uma situação propícia à mudança, pois pode eliminar os interesses criados que a impediam, ou podem debilitá-los a ponto de os interessados compreenderem que seus privilégios já não têm mais o peso que tinham antes. Um exemplo do primeiro caso é o resultado posterior de algumas guerras: Alemanha e Japão, derrotadas na II Guerra Mundial, cresceram no pós-guerra com taxas superiores à dos vencedores do conflito. Pode ser que, embora sua infraestrutura tivesse sido destruída, os grupos de pressão, cujos privilégios travavam o crescimento econômico, também tinham sido eliminados. No segundo caso, pode ser que a multiplicação dos privilégios acelere a crise e, quando ela chega, perdem seu valor: ter proteção tarifária é um privilégio para quem a possui, mas não para os outros particularmente, nos insumos essenciais; se todos têm essa proteção, não há tanta resistência à mudança nem à possibilidade de mantê-los.

É certo que uma crise não garante mudanças - muito menos positivas - no curto ou longo prazo; todavia, as oportunidades de mudança são maiores, propostas distintas competirão entre si e será adotada aquela que consiga um novo consenso, como foi mostrado nos gráficos anteriores. Na perspectiva de Kirzner, o empreendedor institucional - seja político, de políticas ou de ideias - entende que as condições mudaram e que há espaço para suas propostas.

Se, por um lado, a existência de uma crise facilita a mudança, já que os próprios cidadãos a estão pedindo, isso não define a direção dessa mudança. Tudo dependerá da interpretação que for feita sobre a origem da crise e suas causas.

Tal fato levou alguns empreendedores institucionais, políticos ou intelectuais, a desejar que crises ocorram, para que surjam oportunidades para suas propostas. No entanto, não só a direção dessa mudança não é garantida, como também a crise pode cobrar um preço muito alto e a proposta triunfante pode não ser nenhum placebo.

\section{Resistência à mudança}

Os problemas de incentivos e informação que tornam possível o êxito das iniciativas dos lobistas existem porque os benefícios são concentrados e os custos, dispersos. Isto faz com que os que esperam receber um privilégio estejam, primeiro, muito bem informados sobre o tema e os procedimentos para obtê-lo, enquanto o eleitor em geral não tem motivos para tal. O primeiro tem um incentivo forte, já que o privilégio costuma ser economicamente muito rentável. O segundo enfrenta um custo relativamente menor quando se analisa um privilégio de forma separada, embora, certamente, tenha que arcar com um custo muito alto quando se considera o conjunto de privilégios de todos os grupos de interesse.

Essa "lei" econômica se inverte quando ocorre uma mudança para eliminar ou reduzir esses privilégios. Neste caso, os custos são concentrados e os benefícios, dispersos, o que explica o alto nível de interesse e mobilização do setor afetado diante da possibilidade de mudança, e maior passividade do lado dos potenciais favorecidos. 
Vejamos um exemplo. Em muitos países, os professores do setor público obtiveram uma série de privilégios, entre os quais a possibilidade de solicitar vários tipos de licenças, fazendo com que, em muitos casos, eles não estejam trabalhando, senão utilizando alguma delas. No final das contas, são necessários vários professores para um mesmo cargo. Se um governo quer reduzir ou eliminar esses privilégios, que não existem em outros empregos, enfrentará a forte resistência dos professores que, por serem afetados diretamente, estarão informados sobre o tema e dispostos a resistir a qualquer reforma. Os eleitores em geral, que seriam os mais favorecidos por um sistema educacional mais eficiente e menos oneroso para seus filhos, e menos tributação geral, têm pouca motivação para se informar e, ao mesmo tempo, menos incentivo para defender a mudança proposta.

Isto explica porque os "interesses criados" costumam ser muito ativos impedindo mudanças. Outros exemplos não tão populares são o dos empresários que querem manter a proteção contra as importações e o dos legisladores que resistem à perda ou redução de suas aposentadorias privilegiadas. Como o Estado se tornou uma grande fonte de privilégios, sempre há grupos de interesse dispostos a resistir a uma mudança que lhes prejudiquem. Como mencionado antes sobre as crises, essa resistência se reduz apenas em situações de crise, porque, nessas circunstâncias, não há como pagar esses privilégios, restando pouco a ser defendido.

\section{A pandemia do coronavírus}

Uma crise, portanto, convida à mudança porque provoca as pessoas a refletir sobre sua situação e a sociedade em que vivem. Por outro lado, enfraquece a resistência à mudança. A atual pandemia representa uma crise totalmente inesperada. $\mathrm{O}$ mercado das ideias, sobretudo de ideias para enfrentar uma situação dessas, era muito pequeno, discutido somente por especialistas e alguns funcionários de governos. Nem sequer era um tema prioritário para a própria Organização Mundial da Saúde (OMS), criticada hoje por desperdiçar recursos em temas como o tabagismo e a mudança climática, e não em problemas como esse, de sua clara competência. Esse pequeno mercado funcionava como descrito anteriormente, com uma distribuição normal, um consenso determinado e opiniões dissidentes de ambos os lados.

A crise fez explodir esse mercado, tornando-o grande, motivado pela demanda dos meios de comunicação e da população por dados, conhecimento e opiniões. A primeira reação, comum a todas as sociedades, foi exigir de parte dos dirigentes políticos. Definitivamente, o instrumento mais próximo e imediato que precisa funcionar é o sistema de saúde pública. Ao fazer isso, surgem algumas polêmicas no mercado de ideias: uma delas relacionada com a severidade de uma quarentena versus a possibilidade de manter certas liberdades individuais e confiar na responsabilidade individual. Com o tempo, surge outra, sobretudo em países com quarentenas mais rigorosas: qual é o custo econômico, em termos de contração da atividade, que estamos dispostos a pagar para combater a pandemia? 
De alguma forma, elas serão resolvidas, ou essa curva de distribuição normal, que era pequena, crescerá, podendo-se inclinar para um lado ou outro.

Isto é o que pode gerar algum tipo de impacto institucional no futuro. A curva pode se mover como o gráfico da Figura 3, para a esquerda, refletindo a preferência de maior parte da opinião pública pela presença e controle estatal, pode ficar como está ou poder se mover para a direita, sinalizando a preferência por uma maior responsabilidade individual.

Nos casos de crises econômicas, o debate é focado nas causas. Apresentam-se diferentes explicações e, conforme a causa que for aceita, implementam-se soluções de acordo. Quer dizer, se o entendimento é o de que a causa foi um excesso de gasto público e emissão monetária, como ocorreu em muitos países da América Latina na década de 1980, podemos ter soluções como as vistas na década de 1990 (privatizações, planos anti-inflacionários, convertibilidade, dolarização). Se, pelo contrário, conclui-se que a razão foi o neoliberalismo, o consenso de Washington e o FMI, daremos um passo atrás, optando, como na década de 2000, por estatizações, mais impostos e regulações. Curiosamente, no caso da crise de pandemia desatada pela Covid-19, o centro da discussão não é a origem do vírus, mas as soluções aplicadas: vemos países que atuaram de forma mais autoritária, impondo sérias limitações aos direitos individuais como quarentenas rigorosas, toques de recolher, delegação de poderes ao executivo (que enfraquece a divisão de poderes) e controles à imprensa; e outros que mantêm esses direitos básicos, sugerindo, e não impondo, o isolamento e o distanciamento social, mas sem prejudicar o direito de ir e vir e a atividade produtiva.

Esse debate só começou e se estenderá por muito tempo. A pandemia passará, mas é provável que o debate nunca termine. Seu resultado impactará a mudança institucional futura. Embora haja muitas outras coisas que considerar e dados que conflitem entre si, é provável que a opinião pública seja guiada por indicadores simples, como a quantidade de mortes por país, para chegar a uma conclusão e a uma preferência por um papel maior ou menor do Estado. É certo que basear tal decisão num único dado ou conjunto deles gerará muito debate. Se o desempenho for melhor em países com políticas autoritárias, outros poderão argumentar que, mesmo assim, um nível maior de liberdade e respeito a direitos é preferível por uma série de outros motivos, entre os quais o de que ela gera mais progresso e melhores oportunidades para todos. O outro lado apresentará argumentos similares: mesmo que o desempenho desses países frente à pandemia tenha sido pior, mais Estado é necessário para reduzir a desigualdade. Para nossa discussão, o importante é para que lado irá a opinião pública, o que definirá o rumo da mudança institucional. 


\section{Conclusão}

A mudança institucional anda junto com as ideias e valores que predominam em um determinado momento na sociedade. Essas competem no "mercado de ideias", onde empreendedores institucionais, tanto de ideias quanto de políticas, competem para satisfazer a demanda. Nesse mercado, encontramos agentes com características similares às dos empreendedores nos mercados de bens e serviços.

Esses empreendedores constatam que o tamanho do mercado aumenta em tempos de crise, já que os consumidores querem entender as causas que originaram a situação que os preocupa. Nesse ambiente, a concorrência de ideias define o rumo posterior que a sociedade tomará; porém, a existência da crise não determina o rumo que será seguido.

A pandemia do coronavírus é um desses casos de crise, em geral inesperado. O impacto na "opinião pública" do mundo foi enorme. A primeira reação foi a de exigir ação e reação imediatas dos governos. É lógico, o Estado assumiu essa há séculos, e as pessoas exigem que aja. Essa exigência se estenderá para além da pandemia. Tudo será como era antes, ou haverá uma reação a favor de maior respeito aos direitos individuais? A hipótese presente neste artigo é a de que, diferentemente das crises econômicas, nesta, a opinião pública prestará atenção aos resultados de diferentes políticas e não à origem da crise, e conforme julgue ter sido o desempenho de ambos os lados, orientará suas demandas de mudança institucional em determinado sentido.

\section{Referências}

ACEMOGLU, D.; EGOROV, Georgy; SONIN, Konstantin. A Political Theory of Populism. Working Paper 1121. Department of Economics. Boston: MIT, 2011.

ACEMOGLU, D; JOHNSON, Simon; ROBINSON, James A. The Colonial Origins of Comparative Development: An Empirical Investigation. American Economic Review, v. 91, Dic, p. 1369-1401, 2001.

ARMSTRONG, H.; READ, R. The Determinants of Economic Growth in Small States. The Round Table, v. 368, p. 99-124, 2003.

BAUMOL, William J. Entrepreneurship: Productive, Unproductive and Destructive. Journal of Political Economy, v. 98, n. 5, 1990.

BETHEL, Tom. The Noblest Triumph: Property and Prosperity through the Ages. Londres: St. Martin's Griffin, 1998.

BRENNAN, Geoffrey; BUCHANAN, James. La razón de las normas: Economía Política Constitucional. Madrid: Unión Editorial, 1987.

BUCHANAN, James M. Los límites de la libertad: entre la anarquía y el Leviatán. Buenos Aires: Katz Editores, 2009.

COASE, R. H. The Market for Goods and the Market for Ideas. En Essays on Economics and Economists. Chicago: The University of Chicago Press, 1994. 
CONVERSE, Philip E. The nature of belief systems in mass publics. Critical Review, v.18, n. 1-3, p. 1-74, 2006 [1964].

DEMSETZ, Harold. Hacia una teoría de los derechos de propiedad. American Economic Review, v. 57, May, 1967.

DE SOTO, Hernando. The Other Path: The Economic Answer to Terrorism. Lima: Perseus Book Group, 1986.

. The Mystery of Capital: Why Capitalism triumphs in the West and Fails Everywhere Else. Nova Iorque: Basic Books, 2000.

DIAMOND, Jarred. Guns, Germs and Steel: The Fates of Human Societies. New York: W.W. Norton \& Co, 1999.

DUFFY, Michael. Jerry Falwell, Political Innovator. Time Magazine, 2007. Disponible en: http://www.time.com/ time/nation/article/0,8599,1621300,00.html. Accesso: 15 may 2007.

EASTERLY, W.; KRAAY, A. Small States, Small Problems? Income, Growth, and Volatility in Small States. World Development, v. 28, n. 11, 2000.

EASTERLY, W.; ROSS, Levine. Tropics, Germs and Crops: How Endowments Influence Economic Development. NBER Working Paper 9106. Cambridge: National Bureau of Economic Research, 2002.

FORS, Heather Condon. Island Status, Country Size and Institutional Quality in Former Colonies. Working Papers in Economics. School Of Business, Economics And Law, Göteborg University, 2007.

FRANÇOIS, Abel. The Political Entrepreneur and the Coordination of the Political Process: A Market Process Perspective of the Political Market. The Review of Austrian Economics, v. 16, n. 2/3, 2003.

FRANKEL, J.; ROMER, D. Does trade cause growth? American Economic Review, v. 89, p. 379-99, 1999.

FRIEDMAN, Milton; FRIEDMAN, Rose D. La corriente en los asuntos de los hombres. Revista Libertas, v. 6, n. 11, Oct, 1989.

FU-LAI YU, Tony. An Entrepreneurial Perspective of Institutional Change. Constitutional Political Economy, v. 12, Sep, p. 217-236, 2001.

GALLUP, John Luke; SACHS, Jeffrey; Andrew D. Mellinger. Geography and Economic Development. Annual World Bank Conference on Development Economics. Washington, DC, 1998.

GWARTNEY, James; HOLCOMBE, Randall; LAWSON, Robert. Economic Freedom, Institutional Quality and Cross-Country Differences in Income and Growth. Cato Journal, v. 24, n. 3, 2004.

HAYEK, Friedrich A. The Trend of Economic Thinking. Economica, v. 13, May, p. 121 - 137, 1933.

. The Intellectuals and Socialism. The University of Chicago Law Review, Spring, p. 417- 420, 1949.

Capitalism and the Historians. Chicago: Chicago University Press, 1954.

. The Constitution of Liberty. Chicago: The University of Chicago Press, 1960.

HALL, John A. Power and Liberties: The Causes and Consequences of the Rise of the West. California: University of California Press, 1985.

HENREKSON, Magnus. Entrepreneurship: A Weak Link in the Welfare State. Industrial and Corporate Change, v. 14, n. 3, Mar, p. 437-467, 2005.

HOFSTED, Geert; GUERT, Jan; MINKOW, Michael. Cultures and Organizations: Software of the Mind. Nova Iorque: McGraw-Hill, 2010. 
HOLCOMBE, Randall G. Political Entrepreneurship and the Democratic Allocation of Economic Resources. The Review of Austrian Economics, v. 15, n. 2/3, p. 143-159, 2002.

JONES, E. L. The European Miracle: Environments, Economies and Geopolitics in the History of Europe and Asia. Cambridge: Cambridge University Press, 1981.

KEYNES, John Maynard. The General Theory of Employment, Interest and Money. London: Macmillan, 1939. KIRZNER, Israel M. El significado del proceso de mercado. Libertas Buenos Aires: ESEADE, v. 27, Año XIV, Oct, 1997.

KRAUSE, Martín. Índice de Calidad Institucional. Londres: International Policy Network, 2008.

. El Foro y el Bazar: economía, instituciones y políticas públicas. S/l, en publicación, 2013.

LANDES, D. S. The Wealth and Poverty of Nations: Why Some Are So Rich, and Some So Poor. New York: W. W. Norton, 1998.

LA PORTA, Rafael; LOPEZ-DE-SINALES, Florencio, SHLEIFER, Andrei. The Quality of Government. Working Paper 6727. Cambridge: National Bureau of Economic Research., 1998. 2008.

The Economic Consequences of Legal Origins. Journal of Economic Literature, v. 46, n. 2, p. 285-332,

LEIGHTON, Wayne A.; LÓPEZ, Edward J. Madmen, Intellectuals and Academic Scribblers: The Economic Engine of Political Change. Stanford: Stanford University Press, 2013.

LI, D. et al.. Institutional Entrepreneurs. The American Economic Review, v. 96, n. 2, May, 2006.

MALLABY, Sebastian. The Politically Incorrect Guide to Ending Poverty. Atlantic Magazine, Jul/Aug, 2010.

MEHLIMS, Halvor; MOENE, Karl; TORVIK, Ragnar. Cursed by Resources of Institutions?. Working Paper Series. Department of Economics. Norway: Norwegian University of Science and Technology, 2005.

MÉNDEZ, S.; CARLOS, H. The Politics of Bank Non-Lending Activities Regulation: A Cross Country and Time Dynamic Study of the Role of Government and Private Industry Groups. Dissertation, 2010. Disponible en: http://papers.ssrn.com/sol3/papers.cfm?abstract_id=1928799. Acceso: 15 may 2007.

MENGER, Carl. El origen de la moneda. Buenos Aires: Libertas Buenos Aires: ESEADE, n., 1871.

MISES, Ludwig von. Human Action: A Treatise on Economics. Yale: Yale University Press, 1949.

. La acción humana. Madrid: Unión Editorial, 1980.

Theory and History. Auburn: The Mises Institute, 2000.

NORTH, D. C. Structure and Change in Economic History. New York: W.W. Norton, 1981.

Press, 1990.

Institutions, Institutional Change, and Economic Performance. Cambridge: Cambridge University 2005.

Understanding the Process of Economic Change. Princeton \& Oxford: Princeton University Press,

NORTH, D. C.; THOMAS, R. P. The Rise of the Western World: A New Economic History. Cambridge: Cambridge University Press, 1973. 
OLSON, M. The Rise and Decline of Nations. New Haven: Yale University Press, 1982.

RODRICK, Dani; SUBRAMANIAN, Arvind; TREBBI, Francesco. Institutions Rule: The Primacy of Institutions over Geography and Integration in Economic Development. NBER Working Paper 9305. Cambridge: National Bureau of Economic Research, 2002.

ROLL, Richard; TALBOTT, John. Political and Economic Freedoms and Prosperity. 2003a. http://www.anderson. ucla.edu/documents/areas/fac/finance/19-01.pdf. Acceso: 15 may 2007.

. Political Freedom, Economic Liberty and Prosperity. Journal of Democracy, v. 14, n. 3, jul, 2003b.

ROSENBERG, Nathan; BIRDZELL JR, E. How the West Grew Rich: The Economic Transformation of the Industrial World. Nova Iorque: Basic Books, Inc, 1986.

ROUGIER, Luis. El genio de Occidente. Madrid: Unión Editorial, 2001.

SACHS, Jeffrey D. Institutions Don't Rule: Direct Effects of Geography on Per Capita Income. NBER Working Paper 9490. Cambridge: National Bureau of Economic Research, 2003a.

Las Instituciones son importantes, pero no para todo: no deben subestimarse el papel que cumplen la geografía y los recursos naturales en el desarrollo. Finanzas y Desarrollo, Fondo Monetario Internacional, Jun, 2003b.

SCHNELLENBACH, Jan. Public Entrepreneurship and the Economics of Reform. Journal of Institutional Economics, v. 3, n. 2, p. 183-202, 2007.

SCHUMPETER, Joseph A. The Theory of Economic Development. Cambridge: Harvard University Press, 1951.

Essays on Entrepreneurs, Innovations, Business Cycles and the Evolution of Capitalism. New Brunswick: Transaction Publishers, 2000.

Capitalism, Socialism and Democracy. New York: Harper Perennial Modern Thought, 2008.

SCULLY, G. W. The Institutional Framework and Economic Development. Journal of Political Economy, v. 96, n. 3, p. 652-62, 1988.

WEBER, Max. The Protestant Ethic and the Spirit of Capitalism: Third Roxbury Edition. Los Angeles: Roxbury Publishing Company, 1920.

WERNER, Karl Ferdinand. Europe and the Rise of Capitalism. S/l, Basic Blackwell, 1988.

WOHLGEMUTH, Michael. Political Entrepreneurship and Bidding for Political Monopoly. In: HENREKSON, Magnus (ed.). Political Economy of Entrepreneurship. Cheltenham: Edward Elgar Publishing, 2008.

RECEBIDO: 23 DE ABRIL 2020

APROVADO: 8 DE MAIO 2020 